\title{
Finite-time integral sliding mode control for chaotic permanent magnet synchronous motor systems
}

\author{
Abdelilah Chibani, Bachir DaAou, AbDelmadjid Godichiche, \\ AHMed Safa, Youcef Messlem \\ Laboratoire de Génie Electrique et des Plasmas \\ LGEP, Université Ibn Khaldoun, Tiaret, Algérie \\ e-mail:abdelilah.chibani@gmail.com
}

(Received: 11.02.2016, revised: 17.08.2016)

\begin{abstract}
In this paper, an integral finite-time sliding mode control scheme is presented for controlling a chaotic permanent magnet synchronous motor (PMSM). The controller can stabilize the system output tracking error to zero in a finite time. Using Lyapunov's stability theory, the stability of the proposed scheme is verified. Numerical simulation results are presented to present the effectiveness of the proposed approach.

Key words: chaos control, control chaotic Permanent Magnet Synchronous Motor, finite-time, sliding mode
\end{abstract}

\section{Introduction}

A permanent magnet synchronous motor (PMSM) plays an important role in industrial applications due to its simple structure, high power density, low maintenance cost, and high efficiency [1-4]. However, investigations show that PMSM displays chaotic behavior when motor parameters lie in a certain range $[3,4]$. Chaos in PMSM, which decreases the system performance, is highly undesirable in most engineering applications.

Several researchers have investigated the problem of control chaos in PMSM [5-16]. Decoupling control [5], entrainment and migration control [6], optimal Lyapunov exponents placement [7], sensorless control [8-10], time delay feedback control [11], feedback control [12], backstepping control [13], passivity control [14], sliding mode control [15], and fuzzy control $[16,17]$. During the last three decades, variable structure systems (VSS) and sliding mode control (SMC) have received significant interest and have become well-established research areas with great potential for practical applications. The theoretical development aspects of SMC are well documented in many books and articles [7, 16, 20, 25, 27, 29, 31].

The principle of the sliding mode control is to forcibly constrain the system [18, 19, 21], by suitable control strategy, to stay on the sliding surface on which the system will exhibit 
desirable features $[24,26,28]$. The advantages of SMC are robustness, computation speed, compact implementation, controller order reduction, disturbance rejection, and insensitivity to parameter variations. The main disadvantage of the SMC strategy is the chattering phenomenon. SMC has been applied in many control fields which include robot control [30], motor control [5, 22], flight control [23], control of power systems [9, 30, 32, 33], and chemical process control [4].

In this paper, an integral sliding mode control law is designed to achieve the finite-time chaos suppression for the permanent magnet synchronous motor system. The finite-time stability of the closed-loop system is proved using the Lyapunov theory.

This article is organized as follows: the dynamic model of PMSM is presented in Section 2; this model is normalized so that PMSM exhibits chaotic behavior under certain conditions. Section 3 describes in detail the proposed approach design and verifies the stability of the controller according to Lyapunov stability. Effectiveness of the proposed schemes is demonstrated by simulation in Section 4. Finally, the conclusion is given in Section 5.

\section{Modeling of permanent-magnet synchronous motor (PMSM)}

The mathematical model of PMSM [3] is given by:

$$
\left\{\begin{array}{l}
\frac{\mathrm{d} \omega}{\mathrm{d} t}=\frac{1}{J}\left(n_{d} \psi i_{q}+n_{p}\left(L_{d}-L_{q}\right) i_{d} i_{q}-T_{L}-\beta \omega\right), \\
\frac{\mathrm{d} i_{q}}{\mathrm{~d} t}=\frac{1}{L_{q}}\left(u_{q}-R i_{d}-\omega L_{d} i_{d}-\omega \psi_{r}\right), \\
\frac{\mathrm{d} i_{d}}{\mathrm{~d} t}=\frac{1}{L_{d}}\left(u_{d}-R i_{d}+\omega L_{q} i_{q}\right),
\end{array}\right.
$$

where $i_{q}, i_{d}$ and $u_{d}, u_{q}$ are three $d$-axis and $q$-axis stator currents and voltage $L_{q}, L_{d}$ are $q$-axis stator inductances, $R$ corresponds to the stator resistor. $J$ is the polar moment of inertia; $\beta$ is the viscous friction constant, $\psi_{r}$ is the rotor magnetic flux linking the stator and $n_{p}$ is the number of pole-pairs, $T_{L}$ represents the external load torque and $\omega$ corresponds to the rotor angular velocity.

By employing an affine transformation $()=.\lambda^{-1}($.$) and a time-scaling transformation,$

$t=\frac{R}{L_{q}} t^{\prime}$, where $\boldsymbol{\lambda}=\left[\begin{array}{ccc}\boldsymbol{\tau} \mathbf{k} & \mathbf{0} & \mathbf{0} \\ \mathbf{0} & \mathbf{k} & \mathbf{0} \\ \mathbf{0} & \mathbf{0} & \mathbf{R} / \mathbf{L}_{\mathbf{q}}\end{array}\right], \quad \tau=\frac{L_{d}}{L_{q}}, \quad k=\frac{\beta R}{L_{q} n_{p} \psi_{r}}, \quad \gamma=\frac{\psi_{r}}{k L_{q}}, \quad \sigma=\frac{\beta L_{q}}{L J}$.

Then system (1) can be transformed to the following form, which is more suited for control-design purpose: 


$$
\left\{\begin{array}{l}
\frac{\mathrm{d} \omega}{\mathrm{d} t}=\sigma\left(i_{q}-\omega\right)-T_{L}, \\
\frac{\mathrm{d} i_{q}}{\mathrm{~d} t}=-i_{q}-i_{d} \omega+\gamma \omega+u_{q}, \\
\frac{\mathrm{d} i_{d}}{\mathrm{~d} t}=-i_{d}+i_{q} \omega+u_{d},
\end{array}\right.
$$

where $\omega$ is the angle speed, $i_{q}$ and $i_{d}$ denote the quadrature and the direct-axis currents of the motor, respectively $\sigma$ and $\gamma$ are the system parameters, $T_{L}$ is the load torque, $u_{q}$ and $u_{d}$ are the quadrature and direct-axis stator voltage components, respectively. In our paper, we only take the case $u_{q}=u_{d}=0$ then, system (2) becomes:

$$
\left\{\begin{array}{l}
\frac{\mathrm{d} \omega}{\mathrm{d} t}=\sigma\left(i_{q}-\omega\right), \\
\frac{\mathrm{d} i_{q}}{\mathrm{~d} t}=-i_{q}-i_{d} \omega+\gamma \omega, \\
\frac{\mathrm{d} i_{d}}{\mathrm{~d} t}=-i_{d}+i_{q} \omega .
\end{array}\right.
$$

Fig. 1 and Fig. 2 illustrate the typical chaotic attractor's behavior of PMSM for a certain range of its parameters. In our paper we choose the case of $(\sigma, \gamma)=(5.45,20)$ and initial condition. $\omega(0)=0.5, i_{q}(0)=0.6, i_{d}(0)=0.5$.
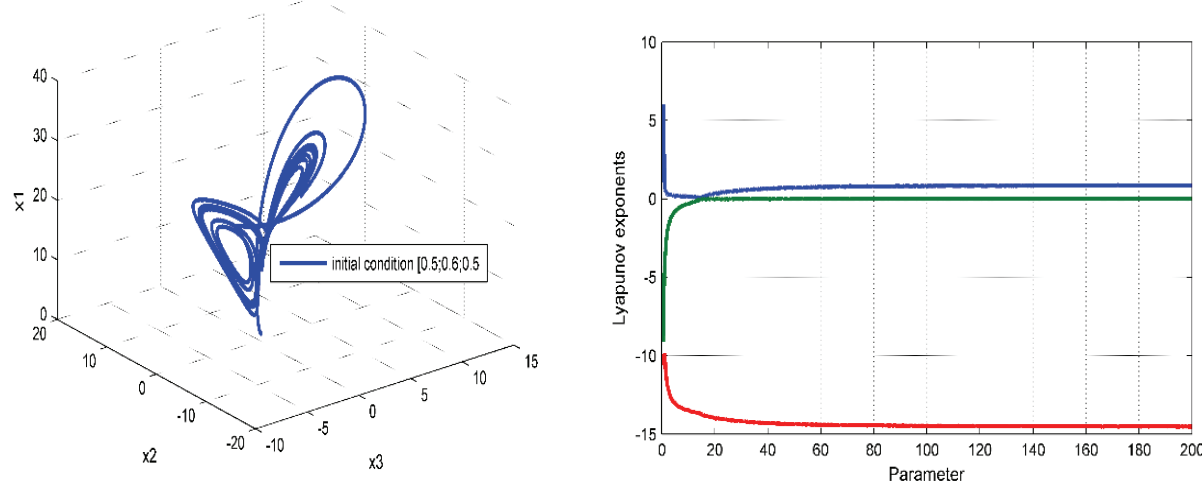

Fig. 1. Characterizations of chaos in PMSM: (a) chaotic attractor; (b) lyapunov exponent

\section{Integral terminal sliding mode control for PMSM}

Consider a nonlinear system as follows:

$$
\dot{x}=f(x)+g(x) u,
$$

where $x \in R, f(x) \in R, g(x) \in R$ and $g^{-1}(x) \neq 0 \in R$. 


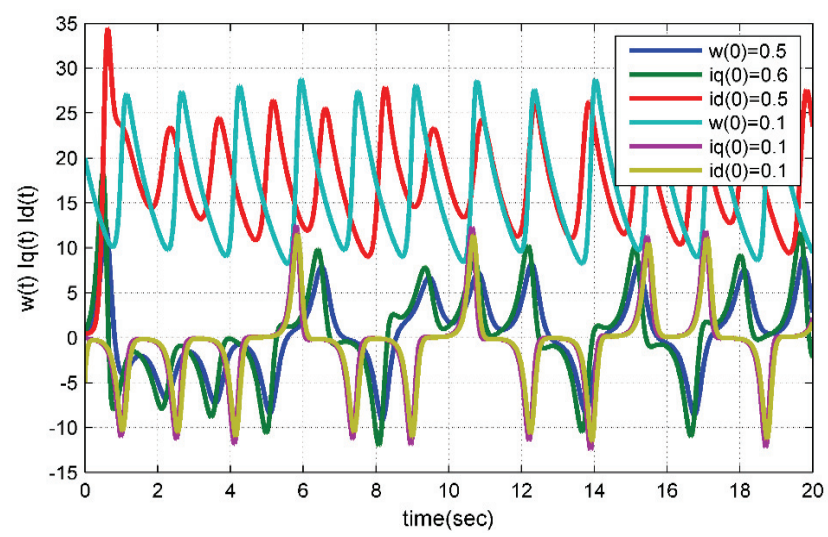

Fig. 2. Time response of the state of PMSM for two initial conditions $(0.5,0.6,0.5)-(0.1,0.1,0.1)$

Let us introduce a sliding variable:

$$
S=x+\theta x_{1},
$$

$$
\dot{x}_{1}=\operatorname{sgn}(x) \text { with } x_{1}(0)=-\frac{x(0)}{\theta}, \text { where } \theta>0 .
$$

According to [20], $x$ will be always kept on $S$. If we guarantee that the surface $S$ is always zero then $x$ will converge to zero in a finite time.

Let $\left(\omega^{r}, i_{q}^{r}, i_{d}^{r}\right)$ denotes an equilibrium point $\left(\omega^{r}, i_{q}^{r}, i_{d}^{r}\right)$. The aim of this paper is to design a controller that stabilizes the system (3) to the equilibrium point and guarantees chaos suppression. We add the single control $u(t)$ to system (3) and then the controlled PMSM system can be expressed by:

$$
\left\{\begin{array}{l}
\frac{\mathrm{d} \omega}{\mathrm{d} t}=\sigma\left(i_{q}-\omega\right), \\
\frac{\mathrm{d} i_{q}}{\mathrm{~d} t}=-i_{q}-i_{d} \omega+\gamma \omega+u, \\
\frac{\mathrm{d} i_{d}}{\mathrm{~d} t}=-i_{d}+i_{q} \omega .
\end{array}\right.
$$

Let the error states of system be:

$$
e_{1}=\omega^{r}-\omega, e_{2}=i_{q}^{r}-i_{q} \text { and } e_{3}=i_{d}^{r}-i_{d}
$$

Then dynamical system can be expressed as:

$$
\left\{\begin{array}{l}
\dot{e}_{1}=\sigma\left(e_{2}-e_{1}\right) \\
\dot{e}_{2}=-\left(e_{1} e_{2}+\omega e_{3}+i_{d} e_{1}\right)-e_{2}+\gamma e_{1}+u, \\
\dot{e}_{3}=e_{1} e_{3}+\omega e_{2}+i_{q} e_{1}-e_{3} .
\end{array}\right.
$$


A suitable sliding surface can be chosen as:

$$
S=e_{2}+\theta e_{2 I}
$$

$\dot{e}_{2 I}=\operatorname{sgn}\left(e_{2}\right)$ with $e_{2 I}(0)=-\frac{e_{2}(0)}{\theta}$.

If $e_{2}$ reaches $S$ it will converge to zero in a finite time

$$
T_{S}=\frac{\left|e_{2}(0)\right|}{\theta} \text {. }
$$

The time derivative of $S$ is

$$
\dot{S}=\dot{e}_{2}+\theta \operatorname{sgn}\left(e_{2}\right)
$$

By letting $S=0$, one can get the equivalent control as:

$$
u_{e q}=e_{1} e_{3}+\omega e_{3}+i_{d} e_{1}+e_{2}-\gamma e_{1}-\theta \operatorname{sgn}\left(e_{2}\right) .
$$

The reaching control is selected as follows:

$$
u_{\text {rech }}=-\mu \operatorname{sgn}(S)
$$

where $\mu>0$ is a positive number.

The sliding mode controller law is designed as:

$$
u=u_{e q}+u_{\text {rech }} .
$$

\section{Theorem}

Consider dynamic error system (7).The integral sliding mode controller (12) yields convergence of $e_{2}$ and $\dot{e}_{2}$ to 0 in a finite time, and the errors $e_{1}$ and $e_{3}$ are globally asymptotically stable at $(0,0)$.

\section{Proof}

Let the Lyapunov function $V(S)$ be defined by:

$$
V(S)=\frac{1}{2} S^{2}
$$

The time derivative of this function with respect to time along (7):

$$
\begin{gathered}
\dot{V}(S)=S \dot{S}, \\
\dot{V}(S)=S\left(-\left(e_{1} e_{3}+\omega e_{3}+i_{d} e_{1}\right)-e_{2}+\gamma e_{1}+\theta \operatorname{sgn}\left(e_{2}\right)+u\right) .
\end{gathered}
$$

Substituting (12) into (15) gives:

$$
\dot{V}(S)=-\mu|S| .
$$

According to the sliding condition [20], $e_{2}$ and $\dot{e}_{2}$ converge to zero in a finite time. After $e_{2}$ has converged to 0 , the dynamical errors $e_{1}$ and $e_{3}$ can be written as: 


$$
\left\{\begin{array}{l}
\dot{e}_{1}=-\sigma e_{1}, \\
\dot{e}_{3}=i_{q} e_{1}-e_{3} .
\end{array}\right.
$$

If the candidate Lyapunov function is defined as:

$$
V(e)=\frac{1}{2}\left(e_{1}^{2}+e_{3}^{2}\right),
$$

then the time derivative of $V(e)$ is:

$$
\begin{gathered}
\dot{V}(e)=e_{1} \dot{e}_{1}+e_{3} \dot{e}_{3}, \\
\dot{V}(e)=-\sigma e_{1}^{2}-e_{3}^{2}+i_{q} e_{1} e_{3} .
\end{gathered}
$$

Inequality (21) can be rewritten as:

$$
\dot{V}(e)=-e^{T} \Gamma e<0,
$$

with $e=\left[\begin{array}{ll}\boldsymbol{e}_{1} & \boldsymbol{e}_{3}\end{array}\right]^{T}$ and $\Gamma=\left[\begin{array}{cr}\boldsymbol{\sigma} & \mathbf{0} \\ -\boldsymbol{i}_{q} & \mathbf{1}\end{array}\right]>0(\sigma>0)$.

\section{Simulation results}

Simulations, using MATLAB Software Package, are carried out to verify the effectiveness of the proposed method. The parametric values of PMSM are the same as those in Section 3. Without loss of generality, we select $\left(\omega^{r}, i_{q}^{r}, i_{d}^{r}\right)=(0,0,0)$ as the desired equilibrium point. The control method takes effect after $t=4.5 \mathrm{~s}$. Fig. 3 shows the dynamic error system states of PMSM and the manipulated signals $u$.

From the results, it can be seen that the proposed integral sliding mode controller structure shows good performance in achieving the output regulation.

Next, we examine the robustness of the proposed controllers in the presence of the model uncertainty and external disturbances. Fig. 4 shows the performances of controllers for $40 \%$ increase in the parameters and external disturbance were added to PMSM: omiga $1=$ $=0.2 \cos (0.3 t)$, omiga $2=0.3 \cos (0.4 t)$, omiga $3=0.6 \cos (0.6 t)$. Therefore, it can be concluded that the proposed control schemes are robust to changes in the parameters and to disturbances acting on the system.

Finally, we examine the robustness of the proposed controllers in the presence of the measurement noise. In this case, white Gaussian noises with variances of 3\% are simultaneously added to the outputs measurements. The system transient's responses for the controller and the control action are shown in Fig. 5. 
a)

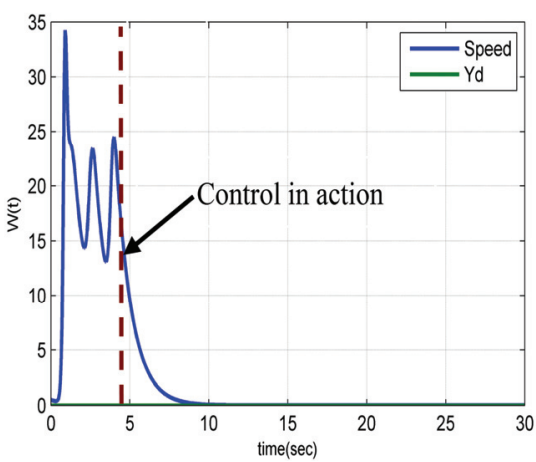

c)

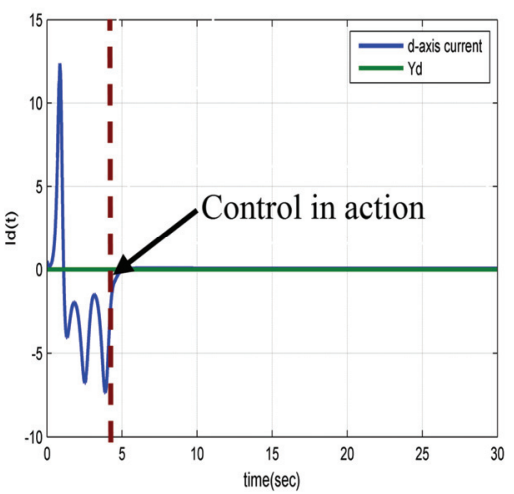

b)

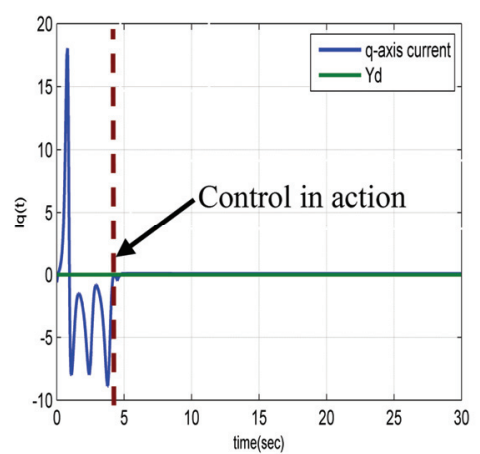

d)

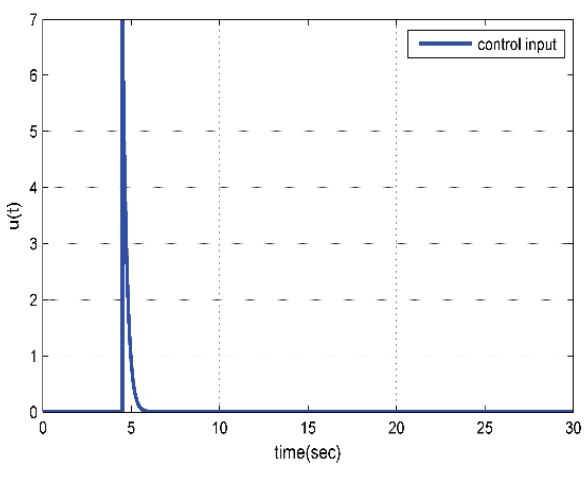

e)

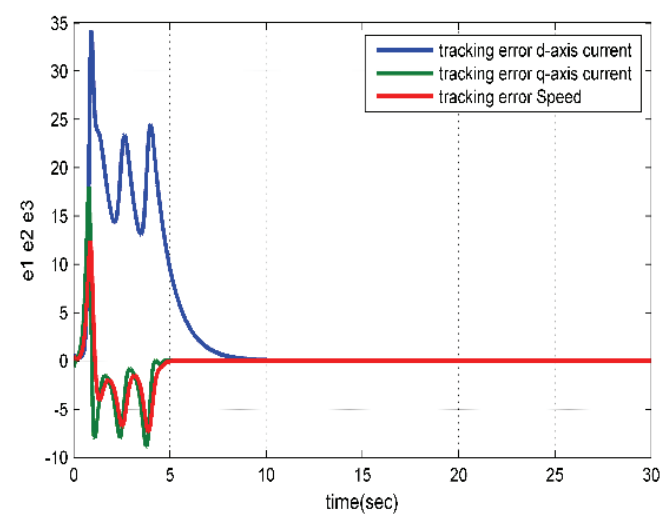

Fig. 3. System responses with the control in action at $t=4.5 \mathrm{~s}$ : (a) speed; (b) $q$-axis current; (c) $d$-axis current; (d) control input; (e) tracking error

It can be seen that the set-point tracking behavior is very satisfactory. Note that the proposed controller maintains the PMSM state in a small neighborhood of the desired value despite the noise on the measurement. 
a)

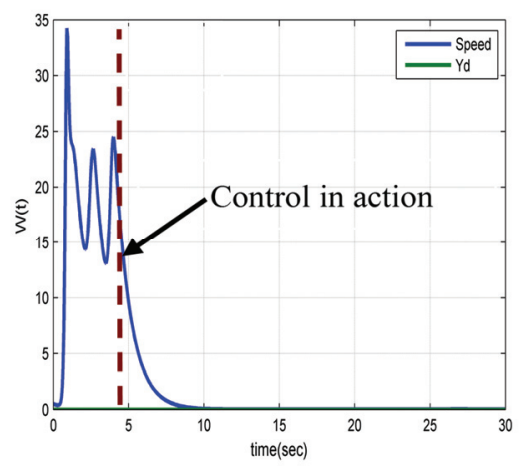

c)

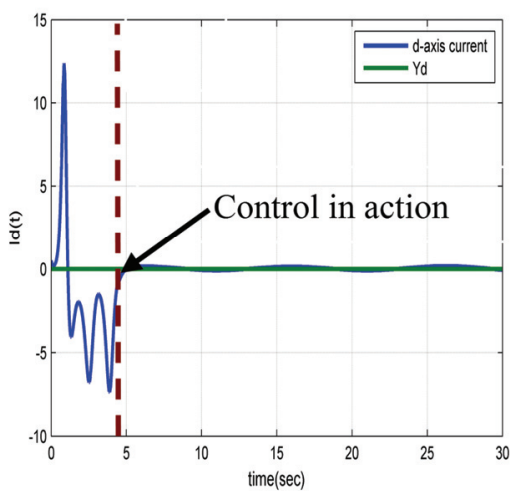

b)

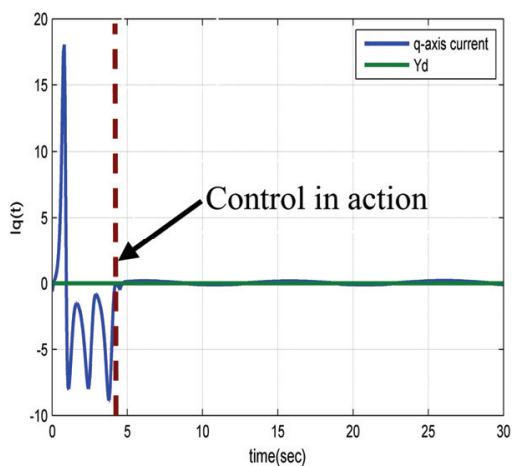

d)

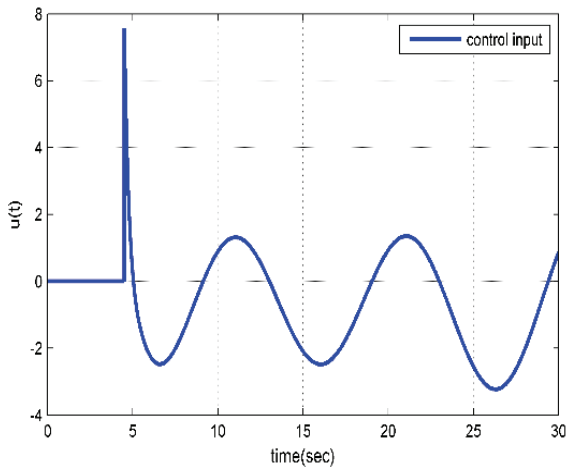

e)

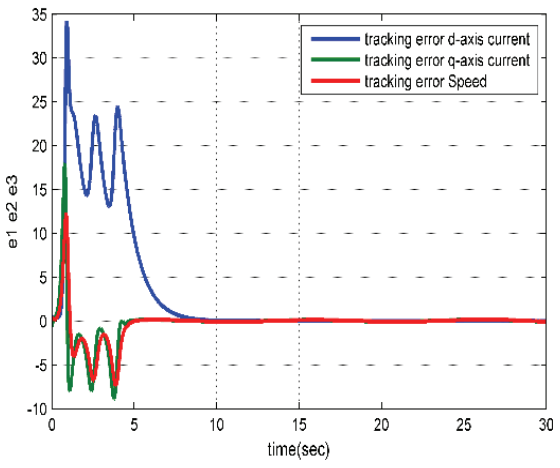

Fig. 4. System responses in the presence of the model uncertainty and external disturbances with the control in action at $t=4.5 \mathrm{~s}$ : (a) speed; (b) $q$-axis current; (c) $d$-axis current; (d) control input; (e) tracking ing error 
a)

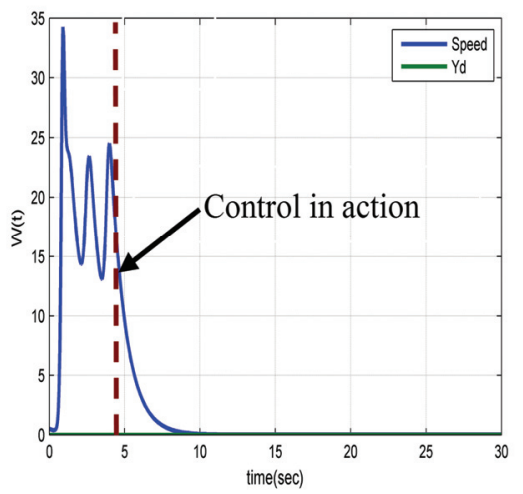

c)

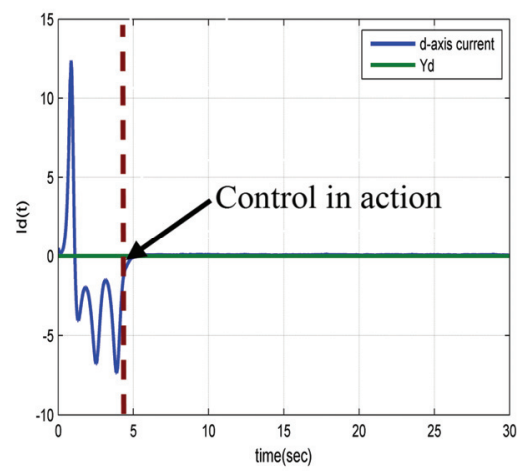

b)

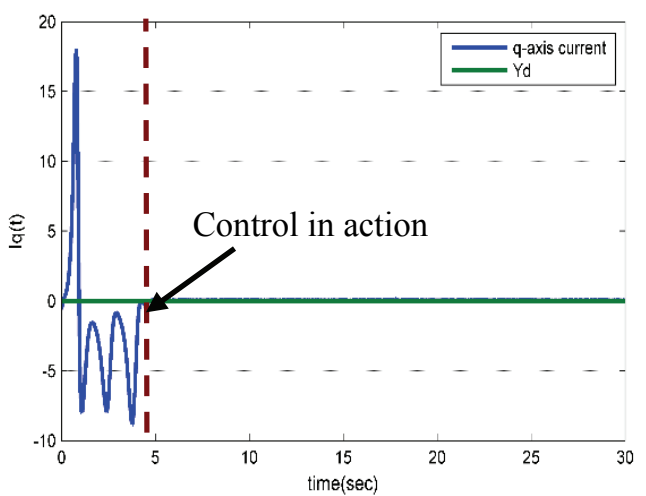

d)

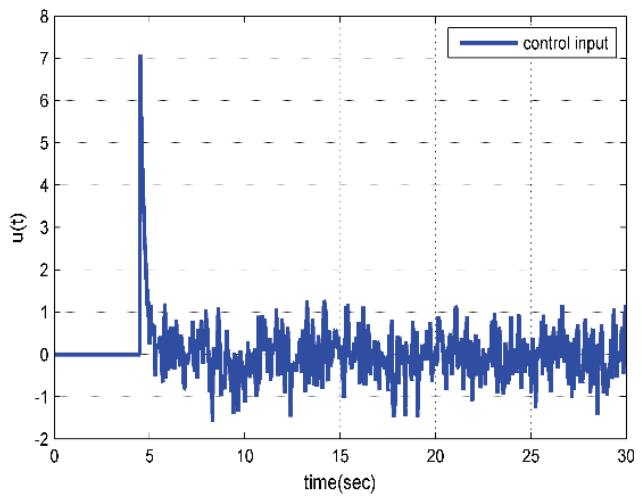

e)

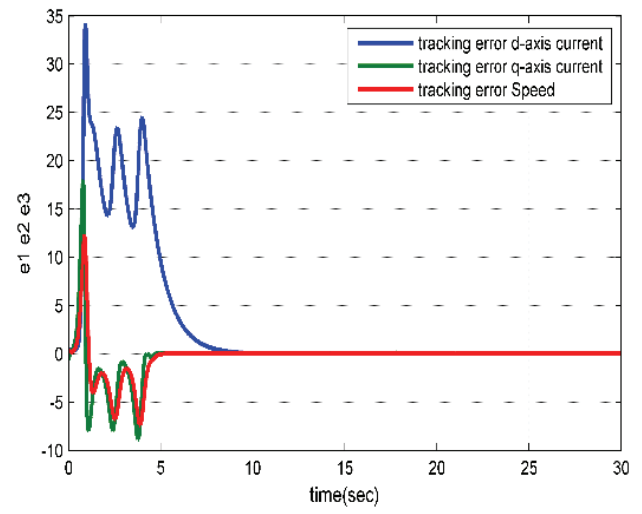

Fig. 5. System responses with the presence of the white noise with the control in action at $t=4.5 \mathrm{~s}$ : (a) speed; (b) $q$-axis current; (c) $d$-axis current; (d) control input; (e) tracking error 


\section{Conclusion}

In this paper, we presented an integral finite-time sliding mode control scheme for a permanent-magnet synchronous motor. The closed-loop stability is proved. Through numerical simulations, we illustrated the feasibility of the designed control system. Moreover, the proposed control exhibits a satisfactory performance when used with disturbance and dynamics uncertainty.

\section{References}

[1] Babak N.M., Farid M.T., Sargos F.M., Mechanical Sensorless Control of PMSM with Online Estimation of Stator Resistance, IEEE Trans. Ind. Appl., vol. 40, no. 2, pp. 457-471 (2004).

[2] Bolognani S., Zigliotto M., Zordan M., Extended-Range PMSM Sensorless Speed Drive Based on Stochastic Filtering, IEEE Trans. Power Electron., vol. 16, no. 1, pp. 110-117 (2001).

[3] Li Z., Park J., Zhang B., Chen G., Bifurcations and chaos in a permanent-magnet synchronous motor, IEEE Trans. Circuits Syst.-I, vol. 49, no. 3, pp. 383-287 (2002).

[4] Jing Z., Yu C., Chen G., Complex dynamics in a permanent-magnet synchronous motor model, Chaos, Solitons and Fractals, no. 22, pp. 831-848 (2004).

[5] Li J., Ren H., Partial decoupling control of chaos in permanent magnet synchronous motor, Control Theory \& Applications, vol. 22, no. 4, pp. 637-640 (2005).

[6] Zhang B., Zhong L., Zongyuan M., Entrainment and Migration Control of Permanent-Magnet Synchronous Motor System, Journal of Control Theory and Applications, vol. 19, no. 4, pp. 53-56 (2002).

[7] Ataei M., Kiyoumarsi A., Ghorbani B., Control of chaos in permanent magnet synchronous motor by using optimal Lyapunov exponents placement, Physics Letters, vol. 374, no. 41, pp. 4226-4230 (2010).

[8] Seok J.K., Lee J.K., Lee D.C., Sensorless speed control of nonsalient permanent-magnet synchronous motors using rotor-position-tracking PI controller, IEEE Trans. Ind. Appl., no. 53, pp. 399-405 (2006).

[9] Wallmark O., Harnefors L., Sensorless control of salient PMSM drives in the transition region, IEEE Trans. Ind. Appl., vol. 53, no. 4, pp. 1179-1187 (2006).

[10] Brock S., Pajchrowski T., Sensorless and energy-efficient PMSM drive for fan application, Arch. Electr. Eng., vol. 62, no. 2, pp. 217-225 (2013).

[11] Ren H.P., Liu D., Li J., Delay feedback control of chaos in permanent magnet synchronous motor, Proceedings of the CSEE, vol. 23, no. 6, pp. 175-178 (2003).

[12] Ren H.P., D Liu., Nonlinear feedback control of chaos in permanent magnet synchronous motor, IEEE Trans. Circuits Syst.-II., vol. 53, no. 1, pp. 45-50 (2006).

[13] $\mathrm{Hu}$ J., Zou J., Adaptive backstepping control of permanent magnet synchronous motors with parameter uncertainties, Control and Decision, vol. 21, no. 11, pp. 1264-1269 (2006).

[14] Wu Z.Q., Tan F.X., Passivity control of permanent magnet synchronous motor chaotic systems, Proceedings of the CSEE, vol. 26, no. 18, pp 159-163 (2006).

[15] Huang C.F., Liao T.L, Chen C.Y, Yan J.J., The design of quasi-sliding mode control for a permanent magnet synchronous motor with unmatched uncertainties, Comp. Math. Appl., vol. 64, no. 5, pp. 1036-1043 (2012).

[16] Wu Z.Q., Optimal fuzzy guaranteed cost control for nonlinear system and its application in permanent magnet synchronous motor chaos system, Proceedings of the CSEE, vol. 23, no. 9, pp. 152-157 (2006).

[17] Li D., Zhang X.H., Yang D., Wang S.L., Fuzzy control of chaos in permanent magnet synchronous motor with parameter uncertainties, Acta Phy. Sin., vol. 58, no.3, pp. 1432-1440 (2009).

[18] Bartolini G., Zolezzi T., Variable structure systems nonlinear in the control law, IEEE Trans. Autom. Control, vol. 30, Issue 7, pp. 681-684 (1985). 
[19] Decarlo R.A., Zak S.H, Matthews G.P., Variable structure control of nonlinear multivariable systems: a tutorial, Proceedings of the IEEE, vol. 76, no. 3, pp. 212-232 (1988)

[20] Utkin V.I., Sliding modes in control and optimization, Springer-Verlag, Berlin (1992).

[21] Hung J.Y., Gao W., Hung J.C., Variable structure control: a survey, IEEE Trans. Ind. Electron., vol. 40, no. 1, pp. 2-22 (1993).

[22] Zinober A.S.I., Variable structure and Lyapunov control, Springer-Verlag, Berlin (1994).

[23] Young K.D., Utkin V.I., Ozguner U., A control engineer's guide to sliding mode control, IEEE Trans. Control Syst. Technol., vol. 7, no. 3, pp. 328-342, (1999).

[24] Koshkouei A.J., Zinober A.S.I., Robust frequency shaping sliding mode control, IEE Proceedings Control Theory Appl., vol. 147, no. 3, pp. 312-320 (2000).

[25] Sira-Ramirez H., Ahmad S., Zribi M., Dynamical feedback control of robotic manipulators with joint flexibility, IEEE Trans. Syst. Man Cybern., vol. 22, no. 4, pp. 736-747 (1992).

[26] Zribi M., Sira-Ramirez H., Ngai A., Static and dynamic sliding mode control schemes for a permanent magnet stepper motor, International Journal of Control, vol. 74, pp. 103-117 (2001).

[27] Alrifai M.T., Zribi M., Sira-Ramirez H., Static and dynamic sliding mode control of variable reluctance motors, International Journal of Control, vol. 77, pp. 1171-1188 (2004).

[28] Sira-Ramirez H., Zribi M., Ahmad S., Dynamical sliding mode control approach for vertical flight regulation in helicopters, IEE Proceedings - Control Theory Appl., vol. 141, pp. 19-24 (1994).

[29] Bengiamin N.N., Chan W.C., Variable structure control of electric power generation, IEEE Trans. Power Apparatus Syst., vol. 101, pp. 376-380 (1982).

[30] Shtessel Y., Zinober A.S.I., Shkolnikov I., Sliding mode control of boost and buck-boost power converters using the dynamic sliding manifold, Int. J. Robust Nonlinear Control, vol. 13, pp. 1285-1298 (2003).

[31] Aguilar R., Martinez-Guerra R., Maya-Yescas R., Temperature Regulation via PI High-Order Sliding-Mode Controller Design: Application to a Class of Chemical Reactor, International Journal of Chemical Reactor Engineering, vol. 7 (2009).

[32] Baba M., Lascu C., Boldea I., Blaabjerg F., Parallel and series 4 switch Z-source converters in induction motor drives, in Proceedings of the International Conference on Optimization of Electrical and Electronic Equipments, Optim (2014).

[33] Lascu C., Blaabjerg F., Super-twisting sliding mode direct torque control of induction machine drives, IEEE Energy Conversion Congress and Exposition ECCE, 2014, pp. 5116-5122 (2014). 